\title{
Association between body mass index and mortality in hospitalised patients with community-acquired pneumonia
}

\author{
Richard Y. Kim¹, Connor Glick², Stephen Furmanek², Julio A. Ramirez ${ }^{2}$ and \\ Rodrigo Cavallazzi ${ }^{1}$
}

Affiliations: ${ }^{1}$ University of Louisville School of Medicine, Dept of Medicine, Division of Pulmonary, Critical Care, and Sleep Disorders Medicine, Louisville, KY, USA. ${ }^{2}$ University of Louisville School of Medicine, Dept of Medicine, Division of Infectious Diseases, Louisville, KY, USA.

Correspondence: Rodrigo Cavallazzi, University of Louisville School of Medicine, Dept of Medicine, Division of Pulmonary, Critical Care, and Sleep Disorders Medicine, 401 E. Chestnut St, Suite 310, Louisville, KY 40202, USA. E-mail: rodrigo.cavallazzidalouisville.edu

ABSTRACT The obesity paradox postulates that increased body mass index (BMI) is protective in certain patient populations. We aimed to investigate the association of BMI and different weight classes with outcomes in hospitalised patients with community-acquired pneumonia (CAP).

This cohort study is a secondary data analysis of the University of Louisville Pneumonia Study database, a prospective study of hospitalised adult patients with CAP from June, 2014, to May, 2016, in Louisville, KY, USA. BMI as a predictor was assessed both as a continuous and categorical variable. Patients were categorised as weight classes based on World Health Organization definitions: BMI of $<18.5 \mathrm{~kg} \cdot \mathrm{m}^{-2}$ (underweight), BMI of 18.5 to $<25 \mathrm{~kg} \cdot \mathrm{m}^{-2}$ (normal weight), BMI of 25.0 to $<30 \mathrm{~kg} \cdot \mathrm{m}^{-2}$ (overweight), BMI of 30 to $<35 \mathrm{~kg} \cdot \mathrm{m}^{-2}$ (obesity class I), BMI of 35 to $<40 \mathrm{~kg} \cdot \mathrm{m}^{-2}$ (obesity class II), and BMI of $\geqslant 40 \mathrm{~kg} \cdot \mathrm{m}^{-2}$ (obesity class III). Study outcomes, including time to clinical stability, length of stay, clinical failure and mortality, were assessed in hospital, at 30 days, at 6 months and at 1 year. Clinical failure was defined as the need for noninvasive ventilation, invasive ventilation or vasopressors within 1 week of admission. Patient characteristics and crude outcomes were stratified by BMI categories, and generalised additive binomial regression models were performed to analyse the impact of BMI as a continuous variable on study outcomes adjusting for possible confounding variables.

7449 patients were included in the study. Median time to clinical stability was 2 days for every BMI group. There was no association between BMI as a continuous predictor and length of stay $<5$ days (chisquared $=1.83$, estimated degrees of freedom $(E D F)=2.74, p=0.608)$. Clinical failure was highest in the class III obesity group, and higher BMI as a continuous predictor was associated with higher odds of clinical failure. BMI as a continuous predictor was significantly associated with 30-day (chi-squared=39.97, $\mathrm{EDF}=3.07, \mathrm{p}<0.001$ ), 6-month (chi-squared=89.42, $\mathrm{EDF}=3.44, \mathrm{p}<0.001$ ) and 1-year (chi-squared=83.97, $\mathrm{EDF}=2.89, \mathrm{p}<0.001)$ mortalities. $\mathrm{BMI} \leqslant 24.14 \mathrm{~kg} \cdot \mathrm{m}^{-2}$ was a risk factor whereas $\mathrm{BMI} \geqslant 26.97 \mathrm{~kg} \cdot \mathrm{m}^{-2}$ was protective for mortality at 1-year. The incremental benefit of increasing BMI plateaued at $35 \mathrm{~kg} \cdot \mathrm{m}^{-2}$.

We found a protective benefit of obesity on mortality in CAP patients. However, we uniquely demonstrate that the association between BMI and mortality is not linear, and no incremental benefit of increasing BMI levels is observed in those with obesity classes II and III.

$@$ ERSpublications

This study assessed the impact of obesity in the outcomes of patients with community-acquired pneumonia. Increasing BMI is associated with decreased long-term mortality. However, the magnitude of the protective benefit plateaus at a BMI of 35. https://bit.ly/2WrLtRo

Cite this article as: Kim RY, Glick C, Furmanek S, et al. Association between body mass index and mortality in hospitalised patients with community-acquired pneumonia. ERJ Open Res 2021; 7: 00736-2020 [https://doi.org/10.1183/23120541.00736-2020].

This article has supplementary material available from openres.ersjournals.com

Received: 8 Oct 2020 | Accepted after revision: 12 Dec 2020

Copyright CERS 2021. This article is open access and distributed under the terms of the Creative Commons Attribution Licence 4.0. 


\section{Introduction}

The obesity paradox postulates that increased body mass index (BMI) is protective in certain patient populations, particularly the elderly and those with chronic diseases $[1,2]$. The link between BMI and mortality is well established in medical literature with disease specific impacts on mortality. Obese individuals are known to have a significantly higher risk of all-cause mortality when compared with normal weight individuals [3, 4]; FrASCA and McElHANEY [5] stated, "In general, obesity decreases both the health span and lifespan, increases premature mortality and significantly increases global healthcare costs".

The effect that BMI has on pneumonia and mortality, however, remains controversial. Literature exists on both sides of the argument to support and deny a positive effect of obesity on pneumonia and mortality. Some studies have identified an increased mortality risk in obese patients with pneumonia with H1N1 influenza and, more recently, severe acute respiratory syndrome coronavirus 2 (SARS-CoV-2) [6-10]. However, other studies have shown a mortality benefit in obese patients with community-acquired pneumonia (CAP). One meta-analysis performed by $\mathrm{N}_{\mathrm{IE}}$ et al. [11] suggested that obese individuals, though at higher risk for developing pneumonia, may have a lower mortality risk. Several studies have also corroborated the "obesity paradox" and its positive effects on mortality in CAP [5, 12]. Despite these differences, it is generally accepted that underweight individuals are at increased risk of developing and dying from CAP [13-15].

Furthermore, current literature on the long-term mortality outcomes of obesity in CAP is limited, with most studies limited to short-term follow-up ( $<30$ days) [12, 16, 17]. To our knowledge, there is only one study that investigates and demonstrates the mortality benefits of obesity in CAP over a longer time period [18]. Additionally, the studies on the mortality benefits of obesity in CAP stratified patients based primarily on only four BMI categories: underweight, normal, overweight and obese. Current medical literature fails to specify the degree of mortality benefit in CAP in different classes of obesity or the continuous spectrum of BMI.

Thus, we aimed to investigate the association of BMI with mortality in hospitalised patients being treated for CAP in hospital, at 30-days, at 6 months and at 1 year. We further investigated the effect of different classes of obesity and the continuous spectrum of BMI on the risk of mortality in patients with CAP.

\section{Methods}

\section{Study design and study population}

This cohort study is a secondary data analysis of the University of Louisville Pneumonia Study (ULPS) database. ULPS was a prospective observational study of all hospitalised adult patients with CAP from June 1, 2014, to May 31, 2016, in the city of Louisville (KY, USA) [19]. Data were prospectively collected by research associates from the division of infectious diseases at the University of Louisville, and quality control was performed.

\section{Inclusion and exclusion criteria}

Patients were diagnosed with CAP if criteria 1,2 and 3 were met. 1) Presence of a new pulmonary infiltrate on chest radiograph and/or chest computed tomography scan at the time of hospitalisation, defined by a board-certified radiologist's reading. 2) At least one of the following: new cough or increased cough or sputum production; fever $>37.8^{\circ} \mathrm{C}\left(100.0^{\circ} \mathrm{F}\right)$ or hypothermia $<35.6^{\circ} \mathrm{C}\left(96.0^{\circ} \mathrm{F}\right)$; changes in leukocyte count (leukocytosis: $>11000$ cells $\mu \mathrm{L}^{-1}$; left shift: $>10 \%$ band forms $\cdot \mathrm{mL}^{-1}$; or leukopenia: $<4000$ cells $\mu \mathrm{L}^{-1}$ ). 3) No alternative diagnosis at the time of hospital discharge that justified the presence of criteria 1 and 2. Patients were excluded if they were under the age of 18 years, did not have a valid Louisville address, did not possess a valid Social Security number or came from the correction system [19, 20].

\section{BMI category definitions}

Patients were placed into the following categories based upon BMI: underweight, normal weight, overweight or obese. Underweight individuals had a BMI of $<18.5 \mathrm{~kg} \cdot \mathrm{m}^{-2}$. Normal weight individuals had a BMI of 18.5 to $<25 \mathrm{~kg} \cdot \mathrm{m}^{-2}$. Overweight individuals had a BMI of 25.0 to $<30 \mathrm{~kg} \cdot \mathrm{m}^{-2}$. Obese individuals had a BMI of $\geqslant 30.0 \mathrm{~kg} \cdot \mathrm{m}^{-2}$. Patients within the obese class were further subclassified into class I, class II and class III. Class I obese individuals had a BMI between 30 and $<35 \mathrm{~kg} \cdot \mathrm{m}^{-2}$. Class II obese individuals had a BMI between 35 and $<40 \mathrm{~kg} \cdot \mathrm{m}^{-2}$. Class III obese individuals had a BMI $\geqslant 40 \mathrm{~kg} \cdot \mathrm{m}^{-2}$. These classifications are consistent with the World Health Organization BMI classifications [21].

\section{Study variables}

All patients were analysed based on four main study outcome variables. Patient demographics were analysed and include age, sex and race. CAP patients were also categorised based on eight main comorbidities. Vital signs and laboratory values on admission were also included in our statistical analysis. Lastly, severity of 
disease was also investigated based on the different clinical findings, such as altered mental status, pleural effusion, need for intensive care unit, need for vasopressors and need for ventilatory support.

\section{Study outcomes}

Time to clinical stability

A patient was defined as clinically stable the day that the following four criteria were met: 1) improved cough and shortness of breath; 2) lack of fever for at least $8 \mathrm{~h} ; 3$ ) improving leukocytosis (decreased at least $10 \%$ from the previous day); and 4) tolerating oral intake with adequate gastrointestinal absorption. Patients were evaluated daily within the first 7 days of hospitalisation to determine the day when clinical stability was reached. Time to clinical stability was dichotomised as within 3 days (early stability) and after 3 days (late stability).

Length of stay

Length of stay was defined in days and calculated for each patient as the day of discharge minus the day of admission. Length of stay was dichotomised as within 5 days (early discharge) and after 5 days (late discharge).

\section{Clinical failure}

Clinical failure was defined as the need for noninvasive ventilation, invasive ventilation, or vasopressors within 1 week of admission.

\section{Mortality}

All-cause mortality was assessed during hospitalisation, at 30 days after admission (early), at 6 months after admission (mid) and at 1 year (late) after admission. Mortality was assessed either through electronic medical records or vital statistics records from the Kentucky Department for Public Health Office of Vital Statistics.

\section{Statistical analysis}

Baseline categorical explanatory variables were summarised as frequencies and percentages. Continuous variables were summarised as means and standard deviations. Differences in baseline patient characteristics between obese and non-obese patients were analysed using a chi-squared test, Fisher's exact test or Mann-Whitney U-test when appropriate and warranted. Differences between obese and non-obese patients' time to clinical stability (TCS) and length of stay (LOS) were analysed with the Kaplan-Meier method, and log-rank tests were applied to evaluate differences between both groups. Generalised additive model (GAM) regression with dichotomous outcomes were performed with smooth curves produced. GAMs are similar to generalised linear models, but instead of producing a coefficient estimate for continuous predictor variables, they may allow smooth curves to model the association of predictor and outcome. For this analysis, all smoothed curves are plotted against the log odds of receiving an outcome with $95 \%$ confidence intervals. This way, BMI could be used to predict categorical outcomes in manner that does not require a linear relationship; the log odds, taken from a smoothed curve, represent the BMI's piece of the regression equation. Potentially confounding variables adjusted for were age, race, sex, history of cancer, history of congestive heart failure, history of stroke, history of renal disease, history of liver disease, history of chronic obstructive pulmonary disease, smoking history, nursing home residence, presence of pleural effusion on chest radiography or computed tomography scan, altered mental status at admission and heart rate, respiratory rate, temperature, systolic blood pressure, blood urea nitrogen, serum sodium, serum glucose and haematocrit on admission. A p-value of $<0.05$ was considered statistically significant.

\section{Results}

\section{Patient characteristics}

Our study included 7449 patients. Of these, $46.2 \%$ were male; $7 \%$ were underweight, 32\% were normal weight, $26 \%$ were overweight and $35.1 \%$ were obese. The obese patients were further stratified into class I (17\%), class II (9\%) and class III (10\%) based on definitions established by the World Health Organization (WHO) [21]. Patient characteristic results for demographics, comorbidities, physical exam findings and disease severity can be seen in table 1 . Interestingly, frequency of the need for intensive care was highest in the class III obesity group (20\%) and lowest in the underweight (16\%), overweight (16\%) and class II obesity groups (16\%). Furthermore, frequency of the need for ventilatory support was highest in the class III obesity group (19\%) and lowest in both the normal weight and overweight groups (12\%).

\section{Time to clinical stability}

The median days to clinical stability was 2 days, which was the same amongst all classes. The percentage of patients with time to clinical stability $\leqslant 3$ days was similar between all groups (see table 2). Using BMI as a continuous predictor and adjusted for confounders, BMI was not significantly associated with time to 
TABLE 1 Patient characteristics on hospital admission

\begin{tabular}{|c|c|c|c|c|c|c|}
\hline Variable & $\begin{array}{l}\text { Underweight } \\
\mathrm{BMI}<18.5 \mathrm{~kg} \cdot \mathrm{m}^{-2}\end{array}$ & $\begin{array}{l}\text { Normal weight } \\
18.5 \leqslant \mathrm{BMI}<25 \mathrm{~kg} \cdot \mathrm{m}^{-2}\end{array}$ & $\begin{array}{c}\text { Overweight } \\
25 \leqslant B M I<30 \mathrm{~kg} \cdot \mathrm{m}^{-2}\end{array}$ & $\begin{array}{c}\text { Obese class I } \\
30 \leqslant B M I<35 \mathrm{~kg} \cdot \mathrm{m}^{-2}\end{array}$ & $\begin{array}{c}\text { Obese class II } \\
35 \leqslant \mathrm{BMI}<40 \mathrm{~kg} \cdot \mathrm{m}^{-2}\end{array}$ & $\begin{array}{l}\text { Obese class III } \\
40 \mathrm{~kg} \cdot \mathrm{m}^{-2} \leqslant \mathrm{BMI}\end{array}$ \\
\hline \multicolumn{7}{|l|}{ Total study population } \\
\hline Pneumonia & $545(7)$ & 2357 (32) & $1932(26)$ & $1250(17)$ & $654(9)$ & $711(10)$ \\
\hline \multicolumn{7}{|l|}{ Demographics } \\
\hline Age years & 75 (62-85) & $72(58-84)$ & $70(57-80)$ & $67(56-77)$ & $62(52-73)$ & $58(47-67)$ \\
\hline Male sex & 213 (39) & $1199(51)$ & $1004(52)$ & $566(45)$ & 255 (39) & $206(29)$ \\
\hline \multicolumn{7}{|l|}{ Race } \\
\hline Black & $107(20)$ & $374(16)$ & $326(17)$ & 277 (22) & $161(25)$ & $230(32)$ \\
\hline White & $434(80)$ & $1940(82)$ & $1574(82)$ & 965 (77) & 482 (74) & $477(67)$ \\
\hline Other & $4(1)$ & $43(2)$ & $32(2)$ & $8(1)$ & $11(2)$ & $4(1)$ \\
\hline \multicolumn{7}{|l|}{ Social and medical history } \\
\hline \multicolumn{7}{|l|}{ Smoking history } \\
\hline Current smoker & $198(36)$ & 774 (33) & $584(30)$ & $390(31)$ & $201(31)$ & $196(28)$ \\
\hline History of smoking & $182(33)$ & 867 (37) & 759 (39) & 468 (37) & $245(38)$ & $239(34)$ \\
\hline Non-smoking history & $165(30)$ & $716(30)$ & $589(31)$ & $392(31)$ & $208(32)$ & 276 (39) \\
\hline Chronic obstructive pulmonary disease & $318(58)$ & $1068(45)$ & $857(44)$ & $574(46)$ & $311(48)$ & 347 (49) \\
\hline Renal disease & $114(21)$ & $699(30)$ & $564(29)$ & 396 (32) & $194(30)$ & $218(31)$ \\
\hline Congestive heart failure & 125 (23) & 594 (25) & 540 (28) & 408 (33) & 208 (32) & 249 (35) \\
\hline Neoplastic disease & 105 (19) & 390 (17) & 242 (13) & $130(10)$ & $67(10)$ & $56(8)$ \\
\hline Nursing home resident & $98(18)$ & $385(16)$ & $248(13)$ & $125(10)$ & $58(9)$ & $73(10)$ \\
\hline Stroke & $67(12)$ & $312(13)$ & $277(14)$ & $153(12)$ & $72(11)$ & $75(11)$ \\
\hline Liver disease & $33(6)$ & $188(8)$ & $126(7)$ & $87(7)$ & $49(8)$ & $45(6)$ \\
\hline \multicolumn{7}{|l|}{ Physical exam findings } \\
\hline Heart rate beats $\cdot \mathrm{min}^{-1}$ & $109(93-122)$ & $106(92-120)$ & $105(91-119)$ & $105(90-119)$ & 105 (93-117) & $104(90-118)$ \\
\hline Respiratory rate breaths $\cdot \min ^{-1}$ & $22(20-28)$ & $22(20-27)$ & $22(20-27)$ & $22(20-27)$ & $22(20-26)$ & $23(20-27)$ \\
\hline Systolic blood pressure $\mathrm{mmHg}$ & $110(95-132)$ & $112(96-130)$ & $115(99-133)$ & $119(102-138)$ & $120(105-141)$ & $122(105-141)$ \\
\hline Temperature ${ }^{\circ} \mathrm{F}$ & $98.8(98.2-99.7)$ & $98.9(98.2-100.2)$ & $99.0(98.2-100.6)$ & $99.0(98.4-100.4)$ & $99.0(98.4-100.2)$ & $99.0(98.3-100.0)$ \\
\hline Temperature ${ }^{\circ} \mathrm{C}$ & $37.1(36.8-37.6)$ & $37.2(36.8-37.9)$ & $37.2(36.8-38.1)$ & $37.2(36.9-38.0)$ & $37.2(36.9-37.9)$ & $37.2(36.8-37.8)$ \\
\hline Haematocrit \% & $34(30-39)$ & $35(31-39)$ & $36(32-40)$ & $36(32-40)$ & $37(33-41)$ & $37(33-40)$ \\
\hline Serum sodium $\mathrm{mEq} \cdot \mathrm{L}^{-1}$ & $136(133-140)$ & $137(134-140)$ & $137(134-140)$ & $137(134-140)$ & $137(135-140)$ & $138(135-140)$ \\
\hline Blood urea nitrogen $\mathrm{mg} \cdot \mathrm{dL}^{-1}$ & $19(13-30)$ & $20(14-31)$ & $19.5(14-29)$ & $19(13-28)$ & $18(13-28)$ & $17(12-28)$ \\
\hline Serum glucose $\mathrm{mg} \cdot \mathrm{dL}^{-1}$ & $130(107-168)$ & $134(110-177)$ & 142 (114-193) & $153(119-211)$ & $156(119-227)$ & $159(121-237)$ \\
\hline \multicolumn{7}{|l|}{ Severity of disease } \\
\hline Pneumonia severity index risk class IV/V & $379(70)$ & $1578(67)$ & 1193 (62) & 710 (57) & $333(51)$ & $323(45)$ \\
\hline Altered mental status & $125(23)$ & $500(21)$ & $380(20)$ & $190(15)$ & $111(17)$ & $101(14)$ \\
\hline Pleural effusion & $187(34)$ & $849(36)$ & 624 (32) & $383(31)$ & $180(28)$ & $184(26)$ \\
\hline Need for intensive care & $86(16)$ & 420 (18) & $314(16)$ & $211(17)$ & $104(16)$ & $140(20)$ \\
\hline Need for vasopressors & $14(3)$ & $71(3)$ & $61(3)$ & $34(3)$ & $12(2)$ & $21(3)$ \\
\hline Need for ventilatory support & $69(13)$ & $282(12)$ & $232(12)$ & $170(14)$ & $97(15)$ & $137(19)$ \\
\hline
\end{tabular}

Data are presented as $\mathrm{n}(\%)$ or median (interquartile range). BMI: body mass index. 
clinical stability $\leqslant 3$ days (chi-squared=1.18, $\mathrm{EDF}=1.00, \mathrm{p}=0.278$ ). See figure 1 and supplementary tables S1a and S1b.

\section{Length of stay}

The median length of stay was 5 days in all groups except for the class II obesity group, which was 4 days. These differences, however, were not deemed clinically significant (see table 2). The percentage of patients whose length of stay was $<5$ days was lowest in the underweight group and highest in the class II obesity group. Using BMI as a continuous predictor and adjusted for confounders, BMI was not associated with length of stay $<5$ days (chi-squared $=1.83, \mathrm{EDF}=2.74, \mathrm{p}=0.608$ ), due to significant overlap in the smoothed curve of log odds and confidence interval on both above and below 0 (see figure 2 and tables S2a and S2b).

\section{Clinical failure}

The percentage of patients who were deemed a clinical failure was highest in the class III obesity group and lowest in the normal weight group (see table 2). Using BMI as a continuous predictor and adjusted for confounders, higher BMI was significantly associated with higher odds of clinical failure (chi-squared=28.08, EDF=1.00, $\mathrm{p}<0.001$, see figure 3 and tables S3a and S3b). Based on the smoothed curve and $95 \%$ confidence interval, BMI was protective at BMI $\leqslant 27.78 \mathrm{~kg} \cdot \mathrm{m}^{-2}$ as the curve and confidence interval corresponded to a log odds of clinical failure entirely below 0 . Also based on the smoothed curve, BMI becomes a risk factor at BMI $\geqslant 28.59 \mathrm{~kg} \cdot \mathrm{m}^{-2}$ as the smoothed curve and confidence interval are entirely above 0 .

\section{Mortality}

The percentage of CAP patients who died was highest in the underweight group and lowest in the class II and III obesity groups for all time points (see table 2). After adjusting for confounding variables, BMI as a continuous predictor was not significantly associated with in-hospital mortality (see tables S4a and $4 \mathrm{Sb}$ ) but was significantly associated with 30 -day (chi-quared $=39.97, E D F=3.07, p<0.001$, see tables S5a and S5b), 6-month (chi-squared $=89.42, \quad \mathrm{EDF}=3.44, \quad \mathrm{p}<0.001$, see tables $\mathrm{S} 6 \mathrm{a}$ and $\mathrm{S} 6 \mathrm{~b}$ ) and 1-year (chi-squared=83.97, EDF=2.89, $\mathrm{p}<0.001$, see tables S7a and S7b) mortalities. For mortality at 30 days, BMI $\leqslant 22.93$ was a risk factor as the smoothed curve and $95 \%$ confidence interval for the log odds remain entirely above 0. BMI was protective between 26.57 and $38.69 \mathrm{~kg} \cdot \mathrm{m}^{-2}$, as the smoothed curve and $95 \%$ confidence interval for the log odds are entirely below 0 . For mortality at 6 months, BMI $\leqslant 23.74$ was similarly a risk factor for mortality and BMI between 26.97 and $49.19 \mathrm{~kg} \cdot \mathrm{m}^{-2}$ was protective. For mortality at 1 year, BMI $\leqslant 24.14 \mathrm{~kg} \cdot \mathrm{m}^{-2}$ was a risk factor for mortality and BMI $\geqslant 26.97 \mathrm{~kg} \cdot \mathrm{m}^{-2}$ was protective. See figure 4 .

\section{Discussion}

Our study demonstrates that obesity is associated with decreased mortality in patients with CAP. Our comprehensive analysis of obesity adds to the literature the fact that after patients reach class II obesity, there is no incremental benefit of increasing BMI. The degree of the observed benefit is not linear as the magnitude of the protective benefit of an increased BMI plateaus at a BMI of $35 \mathrm{~kg} \cdot \mathrm{m}^{-2}$ (end spectrum of class I obesity). In other words, class II/III obesity would not confer additional benefit compared to class I, but class I/II/III would confer a benefit compared with a normal BMI. Another important aspect of this study is the long-term follow-up. In fact, obesity did not have a statistically significant benefit on in-hospital mortality; however, mortality benefits of increased BMI were observed at all other follow-up periods. We found no relationship between obesity and TCS or LOS. Interestingly, obesity was associated with an increased risk of clinical failure, although this did not translate into increased in-hospital mortality.

Our findings support the metanalysis by NIE et al. [11] which found that obese individuals with CAP have lower mortality risk despite increased risk of infection. CHEN et al. [22] performed a similar study looking at CAP patients followed over periods of 30 days, 6 months and 1 year. They also found a mortality benefit in obese patients, particularly at 1 year follow up. BRAUN et al. [18] showed a similar mortality benefit of obesity in 763 CAP patients followed over 6 years. Taken together, these studies indicate that obesity is associated with better outcomes in patients with CAP and point to the same direction as our study. The generalised additive model with smooth curves provided by our study allows for a nuanced assessment of this association, which is not linear.

Theories have attempted to explain the obesity paradox; however, no clear explanation has been proven to explain the counterintuitive benefits obesity may have on mortality in certain populations. It has been proposed that a link between the effects of obesity on the body's immune system and inflammatory state may provide a benefit on long-term prognosis during acute infection [7,8]. Obesity represents a chronic state of inflammation, which affects both pro- and anti-inflammatory biomarkers that may provide some 


\begin{tabular}{|c|c|c|c|c|c|c|}
\hline Variable & $\begin{array}{c}\text { Underweight } \\
\mathrm{BMI}<18.5 \mathrm{~kg} \cdot \mathrm{m}^{-2}\end{array}$ & $\begin{array}{c}\text { Normal weight } \\
18.5 \leqslant \mathrm{BMI}<25 \mathrm{~kg} \cdot \mathrm{m}^{-2}\end{array}$ & $\begin{array}{c}\text { Overweight } \\
25 \leqslant B M I<30 \mathrm{~kg} \cdot \mathrm{m}^{-2}\end{array}$ & $\begin{array}{c}\text { Obese class I } \\
30 \leqslant B M \mid<35 \mathrm{~kg} \cdot \mathrm{m}^{-2}\end{array}$ & $\begin{array}{c}\text { Obese class II } \\
35 \leqslant B M I<40 \mathrm{~kg} \cdot \mathrm{m}^{-2}\end{array}$ & $\begin{array}{l}\text { Obese class III } \\
40 \mathrm{~kg} \cdot \mathrm{m}^{-2} \leqslant \mathrm{BMI}\end{array}$ \\
\hline \multicolumn{7}{|l|}{ Total study population } \\
\hline Pneumonia & 545 (7) & 2357 (32) & $1932(26)$ & 1250 (17) & 654 (9) & $711(10)$ \\
\hline \multicolumn{7}{|l|}{ Outcomes } \\
\hline Time to clinical stability days & $2(1-4)$ & $2(1-4)$ & $2(1-4)$ & $2(1-3)$ & $2(1-4)$ & $2(1-4)$ \\
\hline$<4$ days & $371(68.1)$ & $1714(72.7)$ & $1411(73.0)$ & $947(75.8)$ & $468(71.6)$ & $531(74.7)$ \\
\hline Length of stay days & $5(3-9)$ & $5(3-8)$ & $5(3-8)$ & $5(3-8)$ & $4(3-7)$ & $5(3-8)$ \\
\hline$<5$ days & $222(40.7)$ & $1072(45.5)$ & $852(44.1)$ & $598(47.8)$ & $328(50.2)$ & $343(48.2)$ \\
\hline Clinical failure & 127 (23.3) & $516(21.9)$ & $433(22.4)$ & $290(23.2)$ & $155(23.7)$ & $196(27.6)$ \\
\hline \multicolumn{7}{|l|}{ Mortality } \\
\hline In-hospital & $46(8.4)$ & $170(7.2)$ & $104(5.4)$ & $52(4.2)$ & $28(4.3)$ & $29(4.1)$ \\
\hline 30-day & $116(21.8)$ & 375 (16.2) & 204 (10.7) & $105(8.6)$ & 50 (7.7) & $50(7.1)$ \\
\hline 6-month & $218(41.2)$ & $667(28.8)$ & 404 (21.2) & $204(16.6)$ & 89 (13.8) & $91(12.9)$ \\
\hline 1-year & 260 (49.3) & 859 (37.3) & $526(27.7)$ & $280(22.9)$ & $113(17.6)$ & 135 (19.1) \\
\hline
\end{tabular}


FIGURE 1 Early time to clinical stability ( $\leqslant 3$ days) according to body mass index in hospitalised patients with community-acquired pneumonia.
Early time to clinical stability $(\leq 3$ days)

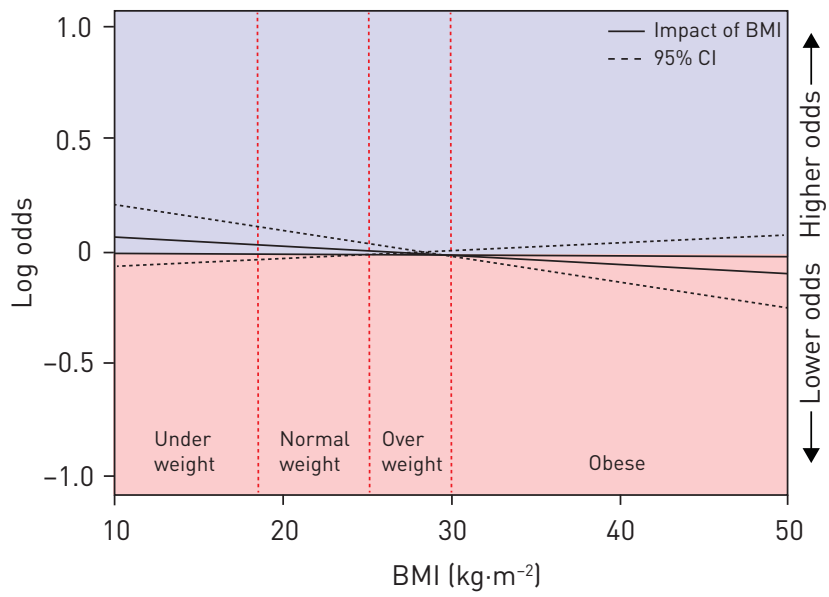

survival benefit. For example, tumour necrosis factor (TNF)- $\alpha$, a proinflammatory cytokine and marker of pneumonia severity, is believed to be dampened by the increased number of TNF- $\alpha$ receptors produced by adipose tissue $[9,10]$. Other adipokines, inflammatory cytokines released by adipocytes, have also shown to play a role in the immune-regulatory response to infections. One such adipokine, leptin, modulates the T-cell response and is a protective component of the immune system. Also, adiponectin has anti-inflammatory properties and may possibly decrease inflammation in the lungs [11, 12]. Our study suggests that the possible beneficial effects are obtained once patients reach class I obesity.

Another theory attempting to explain the obesity paradox involves the amount of lean muscle mass. Obese individuals have more lean muscle mass in addition to increased adiposity and thus have decreased mortality. MARQuis et al. [23] postulates that loss of body mass is indicative of poorer prognosis and higher mortality. Individuals with higher degree of protein degradation, as in that seen in systemic inflammation, may lead to a depletion of essential amino acids necessary for immune defence and tissue regeneration. In addition, muscle mass is found to be inversely proportional to risk of death. ABRAMOWITZ et al. [24] found that the effect of BMI on mortality is attenuated after adjusting for muscle mass. Expanding on this argument, individuals with central adiposity but a normal BMI were found to have higher mortality $[25,26]$. Considering this data, we can speculate that individuals with obesity class I may have decreased mortality due to an increase in muscle mass. Moving from class I to increasing obesity classes may not increase muscle mass further, hence may not offer additional survival benefit.

In our study, patients with obesity were younger and presented with lower severity illness as demonstrated by lower proportion of pneumonia severity index classes IV and V. These findings could also explain why patients with obesity had decreased long-term mortality. This association was present after adjustment for age and other variables that reflect severity of illness. However, residual confounding can remain even after adjustment in regression models. Interestingly, SingANAYAGAm et al. [27] performed a cohort study in 1079

FIGURE 2 Short length of stay (<5 days) according to body mass index in hospitalised patients with community-acquired pneumonia.

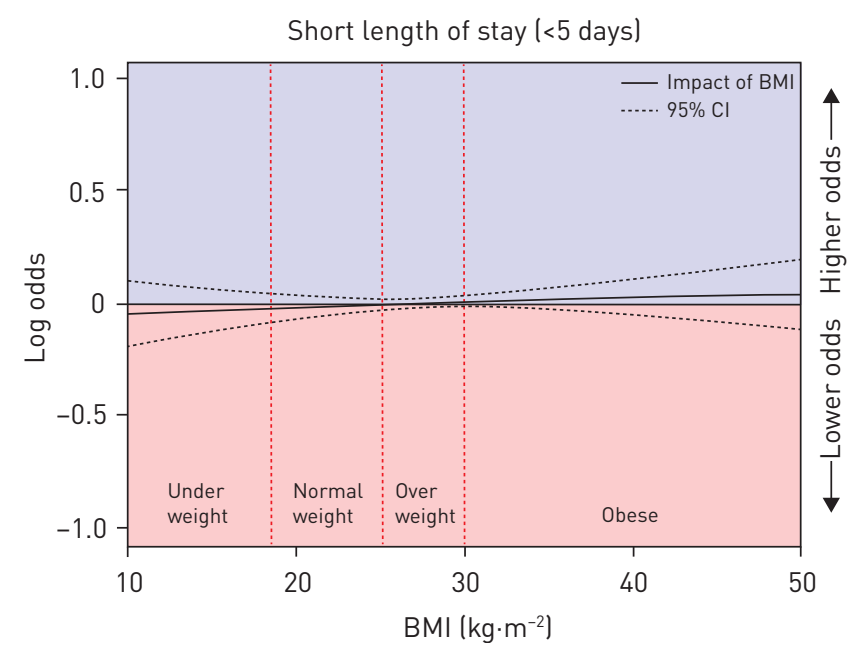


FIGURE 3 Clinical failure according to body mass index in hospitalised patients with community-acquired pneumonia.

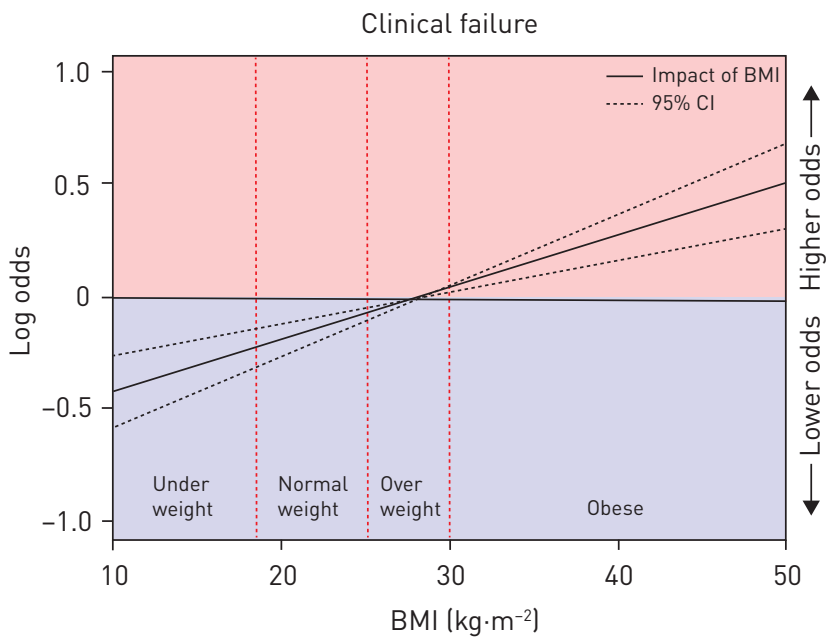

patients with CAP. In their cohort, there was no difference in severity of illness upon admission and in the immediate need for mechanical ventilation or vasopressor support between patients with obesity and non-obese patients with CAP. Despite that, obesity was associated with decreased 30-day mortality in multivariate analysis.

Our study has several strengths and limitations. One main strength of our study, as previously mentioned, was that we were able to study the effects of obesity on mortality in a large cohort of CAP patients. We

In-hospital mortality

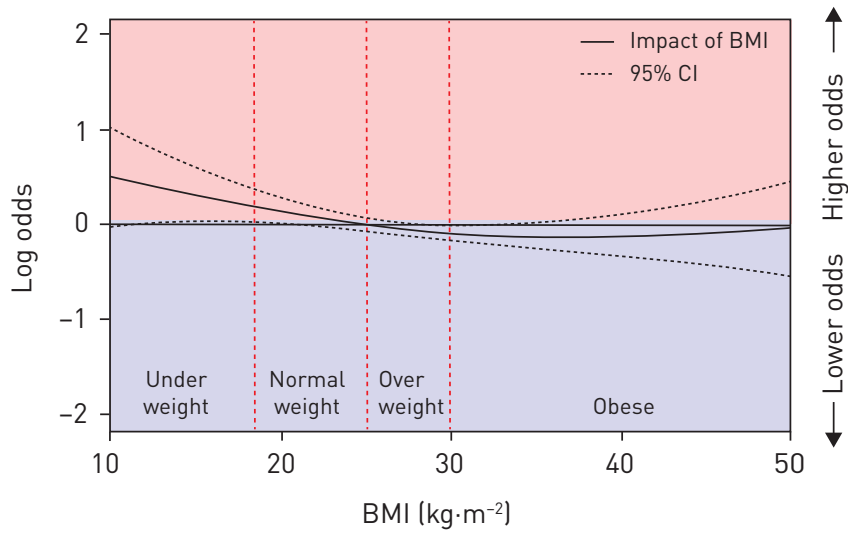

6-month mortality

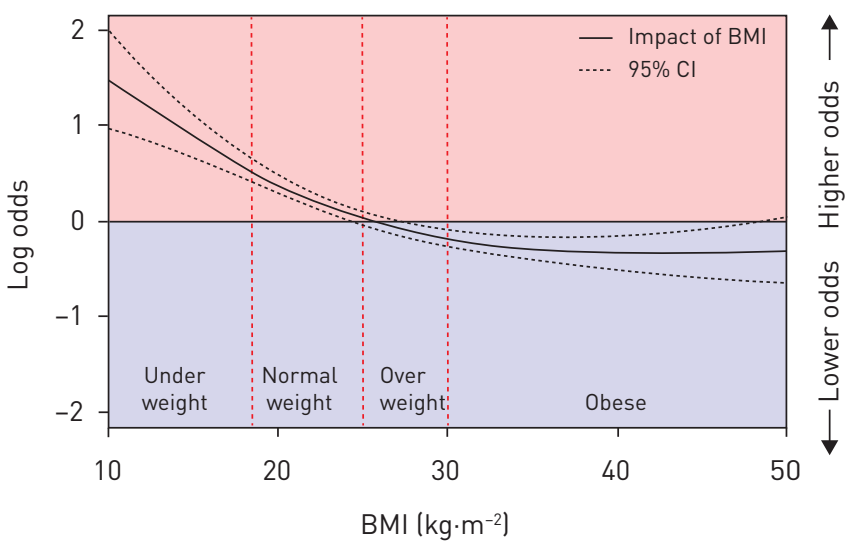

30-day mortality

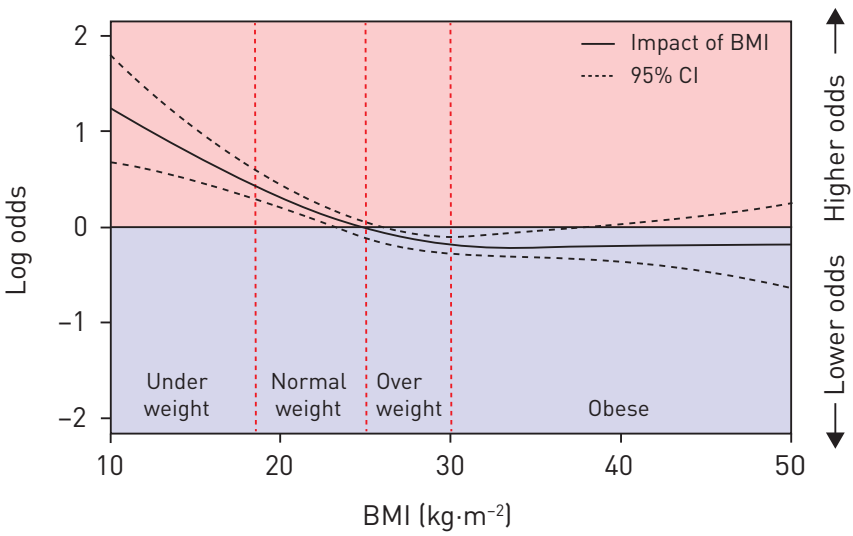

1-year mortality

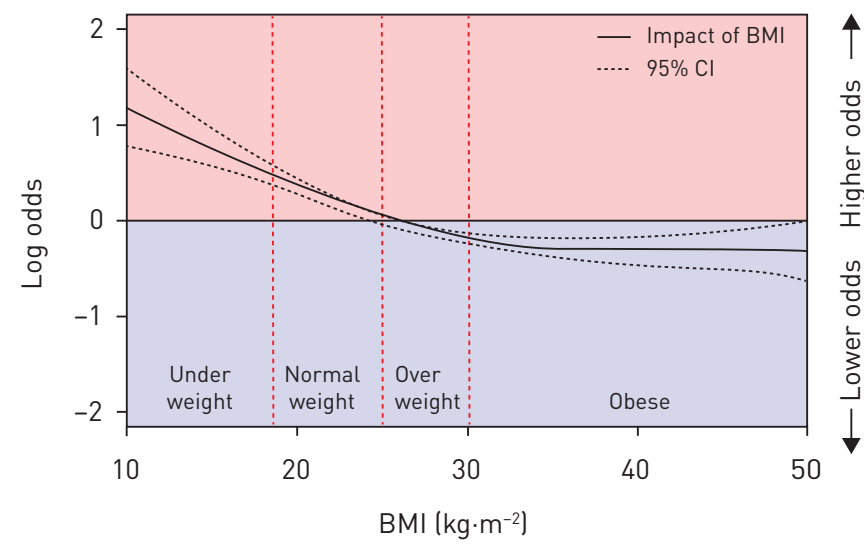

FIGURE 4 Mortality according to body mass index in hospitalised patients with community-acquired pneumonia. 
were also able to investigate this population over time from in hospital to 1-year post discharge. Most studies to date are limited to 30 days. Thirdly, the prevalence of obesity in the studied population (35.1\%) is similar to that seen in the USA (39.8\%), adding to the generalisability of the study's findings across the US population [28]. Our study was able to demonstrate the mortality effect of increased BMI in patients affected by CAP over different classes of obesity, which had not been done with previous studies to date. One limitation is the lack of patients in the extremes of BMI. Furthermore, we did not specify causes of mortality over the 1-year follow- up. Thirdly, despite the patient obesity demographics reflecting that of the USA, our study is limited only to the city of Louisville, KT. A fourth limitation is that we did not measure muscle mass.

The results of our study suggest that future studies that evaluate obesity and mortality need to stratify obesity in different classes. It further suggests that the definition of a "healthy" weight may need to be re-evaluated. Though the mortality benefit of obesity in CAP is observed in the medical literature, the actual physiological mechanism remains in question. Future studies evaluating the actual physiological mechanisms should focus on specific obesity classes. Though unknown, factors such as lean body mass and distribution of adiposity may contribute to the physiological mechanisms involved in the obesity paradox. The differential impact of obesity on outcomes according to different aetiologies of pneumonia should also be further explored, particularly in view of the coronavirus disease 2019 (COVID-19) pandemic. In conclusion, we found a protective benefit of obesity on mortality in CAP patients. However, we uniquely demonstrate that the association between BMI and mortality is not linear, and no incremental benefit of increasing BMI levels is observed in those with obesity classes II and III.

Support statement: Study was supported primarily by the Division of Infectious Diseases, University of Louisville, Kentucky. The parent study was given partial support by Pfizer Inc. Funding information for this article has been deposited with the Crossref Funder Registry.

Author contributions: Design of the study: Julio A. Ramirez; statistical analysis: Stephen Furmanek and Connor Glick; writing: Richard Y. Kim, Julio A. Ramirez, Connor Glick, Stephen Furmanek and Rodrigo Cavallazzi; critical review: Rodrigo Cavallazzi. All authors have reviewed and approved the final version of the manuscript.

Conflict of interest: R.Y. Kim has nothing to disclose. C. Connor has nothing to disclose. S. Furmanek has nothing to disclose. J.A. Ramirez has nothing to disclose. R. Cavallazzi has nothing to disclose.

\section{References}

$1 \quad$ Hainer V, Aldhoon-Hainerova I. Obesity paradox does exist. Diabetes Care 2013; 36: Suppl. 2, S276-S281.

2 Mazimba S, Holland E, Nagarajan V, et al. Obesity paradox in group 1 pulmonary hypertension: analysis of the NIH-Pulmonary Hypertension registry. Int J Obes (Lond) 2017; 41: 1164-1168.

3 Flegal KM, Kit BK, Orpana H, et al. Association of all-cause mortality with overweight and obesity using standard body mass index categories: a systematic review and meta-analysis. JAMA 2013; 309: 71-82.

4 Whitlock G, Lewington S, et al. Body-mass index and cause-specific mortality in 900000 adults: collaborative analyses of 57 prospective studies. Lancet 2009; 373: 1083-1096.

5 Frasca D, McElhaney J. Influence of obesity on pneumococcus infection risk in the elderly. Front Endocrinol (Lausanne) 2019; 10: 71.

6 Vaillant L, La Ruche G, Tarantola A, et al. Epidemiology of fatal cases associated with pandemic H1N1 influenza 2009. Euro Surveill 2009; 14: 19309.

7 Fezeu L, Julia C, Henegar A, et al. Obesity is associated with higher risk of intensive care unit admission and death in influenza A (H1N1) patients: a systematic review and meta-analysis. Obes Rev 2011; 12: 653-659.

8 Fisher-Hoch SP, Mathews CE, McCormick JB. Obesity, diabetes and pneumonia: the menacing interface of non-communicable and infectious diseases. Trop Med Int Health 2013; 18: 1510-1519.

9 Investigators AI, Webb SA, Pettila V, et al. Critical care services and 2009 H1N1 influenza in Australia and New Zealand. N Engl J Med 2009; 361: 1925-1934.

10 Seidu S, Gillies C, Zaccardi F, et al. The impact of obesity on severe disease and mortality in people with SARS-CoV-2: A systematic review and meta-analysis. Endocrinol Diabetes Metab 2020; 4: e00176.

11 Nie W, Zhang Y, Jee SH, et al. Obesity survival paradox in pneumonia: a meta-analysis. BMC Med 2014; 12: 61.

12 Corrales-Medina VF, Valayam J, Serpa JA, et al. The obesity paradox in community-acquired bacterial pneumonia. Int J Infect Dis 2011; 15: e54-e57.

13 Lee J, Kim K, Jo YH, et al. Severe thinness is associated with mortality in patients with community-acquired pneumonia: a prospective observational study. Am J Emerg Med 2015; 33: 209-213.

14 Torres A, Peetermans WE, Viegi G, et al. Risk factors for community-acquired pneumonia in adults in Europe: a literature review. Thorax 2013; 68: 1057-1065.

15 Atamna A, Elis A, Gilady E, et al. How obesity impacts outcomes of infectious diseases. Eur J Clin Microbio Infect Dis 2017; 36: 585-591.

16 Chalmers JD, Mandal P, Singanayagam A, et al. Severity assessment tools to guide ICU admission in community-acquired pneumonia: systematic review and meta-analysis. Intensive Care Med 2011; 37: 1409-1420.

17 Kahlon S, Eurich DT, Padwal RS, et al. Obesity and outcomes in patients hospitalized with pneumonia. Clin Microbiol Infect 2013; 19: 709-716.

18 Braun N, Hoess C, Kutz A, et al. Obesity paradox in patients with community-acquired pneumonia: Is inflammation the missing link? Nutrition 2017; 33: 304-310. 
19 Ramirez JA, Wiemken TL, Peyrani P, et al. Adults hospitalized with pneumonia in the united states: incidence, epidemiology, and mortality. Clin Infect Dis 2017; 65: 1806-1812.

20 Peyrani P, Arnold FW, Bordon J, et al. Incidence and mortality of adults hospitalized with community-acquired pneumonia according to clinical course. Chest 2020; 157: 34-41.

21 WHO. Physical status: the use and interpretation of anthropometry. Report of a WHO Expert Committee. WHO Technical Report Series 854. Geneva: World Health Organization. Available from: https://www.who.int/ childgrowth/publications/physical_status/en/\#: :text=Report\%20of\%20a\%20WHO\%20Expert\%20Committee\&text= Anthropometry\%20provides\%20the\%20single\%20most,predicts\%20performance\%2C\%20health\%20and\%20surviv

22 Chen J, Wang J, Jiang $\mathrm{H}$, et al. Lower long-term mortality in obese patients with community-acquired pneumonia: possible role of CRP. Clinics (Sao Paulo) 2019; 74: e608.

23 Marquis K, Debigare R, Lacasse Y, et al. Midthigh muscle cross-sectional area is a better predictor of mortality than body mass index in patients with chronic obstructive pulmonary disease. Am J Respir Crit Care Med 2002; 166: 809-813.

24 Abramowitz MK, Hall CB, Amodu A, et al. Muscle mass, BMI, and mortality among adults in the United States: a population-based cohort study. PLoS One 2018; 13: e0194697.

25 Sahakyan KR, Somers VK, Rodriguez-Escudero JP, et al. Normal-weight central obesity: implications for total and cardiovascular mortality. Ann Intern Med 2015; 163: 827-835.

26 Braun N, Gomes F, Schutz P. "The obesity paradox" in disease: is the protective effect of obesity true? Swiss Med Wkly 2015; 145: w14265.

27 Singanayagam A, Singanayagam A, Chalmers JD. Obesity is associated with improved survival in community-acquired pneumonia. Eur Respir J 2013; 42: 180-187.

28 Hales CM, Carroll MD, Fryar CD, et al. Prevalence of obesity and severe obesity among adults: United States, 2017-2018. NCHS Data Brief 2020; 360: 1-8. 